\title{
Spatial Distribution Pattern of Pine Trees Killed by Pine Wilt Disease in a Sparsely Growing, Young Pine Stand
}

\author{
Koichi Sone ${ }^{1}$, Keisuke Ohkubo ${ }^{2}$, Toshiyuki Matsuo ${ }^{2} \&$ Kunihiko Hata $^{1}$ \\ ${ }^{1}$ Faculty of Agriculture, Kagoshima University, Kagoshima, Japan \\ ${ }^{2}$ Graduate School of Agriculture, Kagoshima University, Kagoshima, Japan \\ Correspondence: Koichi Sone, Faculty of Agriculture, Kagoshima University, Kagoshima 890-0065, Japan. Tel: \\ 81-099-285-8580. E-mail: sonesun@agri.kagoshima-u.ac.jp
}

Received: August 24, 2012 Accepted: October 16, 2012 Online Published: November 20, 2012.

doi:10.5539/jps.v2n1p36 URL: http://dx.doi.org/10.5539/jps.v2n1p36

\begin{abstract}
We studied the spatial distribution pattern of surviving Japanese black pine trees and those killed by pine wilt disease in 2008 and 2009 in a sparsely growing, young stand on a lava field in Sakurajima, Kagoshima Prefecture, southern Japan. Pine trees were distributed aggregately and formed loose colonies occupying an area of $16-25 \mathrm{~m} 2$. Pine trees killed by pine wilt disease in 2008 and 2009 also occurred in loose colonies of 16-25 $\mathrm{m} 2$ in area. However, the spatial distribution pattern of pine trees killed in 2009 was exclusive to that in 2008 , and killed trees in 2009 occurred in colonies of pine trees where no killed pine trees occurred in 2008. Asymptomatic carrier trees might not have any significant impacts on the spatial pattern of killed trees. This spreading of pine wilt disease might have been caused by the active flight of the Japanese pine sawyer beetles and rapid invasion of the pinewood nematodes into sound trees just after the beetles emerged.
\end{abstract}

Keywords: pine wilt disease, Pinus thunbergii, spatial distribution pattern, wilted trees, young stand

\section{Introduction}

In Sakurajima, Kagoshima Prefecture, southern Japan, stands of the Japanese black pine, Pinus thunbergii, cover a large area of the lower part of the hillside and lava field. On the field where lava exploded in Bunmei (1476) and An'ei (1779) period, large pine trees were growing, and on the fields where the lava exploded in the Taisho (1914) period (T field) and Showa (1946) period, not only large but also small pine trees were growing before the mid-1990's

In 1994, pine wilt disease (PWD) caused by the pinewood nematode (PWN), Bursaphelenchus xylophilus Steiner and Nickle (Nematoda: Aphelenchoididae), recurred 7 years after the previous occurrence in 1987, and began to expand from 1996 (Sone et al., 2002). The damage by PWD was greatest in 2004, and the volume of $P$. thunbergii trees killed by PWD was estimated as $25,800 \mathrm{~m}^{3}$. The damage decreased gradually from $22,690 \mathrm{~m}^{3}$ in 2005 to $12,400 \mathrm{~m}^{3}$ in 2009, and then to $550 \mathrm{~m}^{3}$ in 2010 and to $89 \mathrm{~m}^{3}$ in 2011 (Kagoshima Prefecture Office, personal communications). After the majority of large pine trees died, saplings and/or small pine trees died on lava field every year. The annual changes in the number and spatial distribution pattern of small pine trees killed on the lava field should provide important information to predict the future trend of PWD and to determine effective control practice of PWD in Sakurajima.

The PWN are transported from wilted pine trees to sound pine trees by the adult beetles of the Japanese pine sawyer (JPS), Monochamus alternatus Hope (Coleoptera: Cerambycidae) (Mamiya \& Enda, 1972). Therefore, the spatial distribution pattern of killed trees in a pine stand is considered to be determined by the distribution of pine trees killed the previous year and the dispersal pattern of the JPS beetles. The spatial distribution pattern of pine trees killed by PWD was studied in mature pine stands (Togashi, 1980; Futai, 2003). Togashi (1980) studied the movement of the JPS beetles in a mature pine stand and Shibata (1986) in a young, dense pine stand. The flight activities of the beetles were influenced by the degree of sparseness of the stand (Togashi, 1990b). The spreading pattern of PWD and its mechanisms are assumed to differ between mature (dense) and young (sparsely growing) pine stands, such as those on a lava field in Sakurajima. We surveyed the spatial distribution patterns of small, young pine trees and those killed by PWD on a lava field in Sakurajima. We analyzed the relationship of the spatial distribution patterns of trees killed in successive years, and discussed the characteristics and 
mechanisms of the spreading pattern of PWD.

\section{Study Site and Methods}

We established a study plot, $20 \times 40 \mathrm{~m}$ in area, in October 2010 on the T field in the western part of Sakurajima, Kagoshima Prefecture, southern Japan, where areas of lava explosion during Taisho period remained here and there. The vegetation was in an early stage of succession. The canopy layer was open. The dominant overstory tree was $P$. thunbergii. Other dominant tree species were Rhus sylvestris, Eurya japonica, Hydrangea paniculata, and Raphiolepis umbellate. On the ground surface, Miscunthus sinensis, Polygonum cuspidatum, and Nephrolepis auricutala were growing in patches.

On the T field, PWD was first recorded in 2000 (Sone et al., 2002). Most pine trees taller than $7 \mathrm{~m}$ died by 2005 , and saplings and/or young pine trees shorter than $5 \mathrm{~m}$ were dying every year after 2006. The number of dead pine trees was greatest in 2007, and then continued to decrease (Sone, unpublished data). On the study plot and in its surrounding areas, pine trees killed by PWD were cut down and fumigated with insecticide (Killper, Sankei Chem. Corp., Kagoshima) until 2007, but after 2008, no chemical or mechanical treatment was applied to the dead trees.

We measured the tree height and diameter at breast height (DBH) for all standing pine trees taller than $1.3 \mathrm{~m}$ to examine whether the tree size affected the infestation with the PWN or not, and determined their positions on the study plot. We classified each pine tree as dead or surviving. For dead trees, we determined the year they were killed (before 2008, in 2008, 2009, and 2010) based on the degree of discoloration of needles and decay of tree trunk and other characteristics. We examined the emergence holes of the JPS beetles for all pine trees killed in 2008 and 2009 to detect the position from which the JPS beetles dispersed in 2009 and 2010. We examined the feeding wounds for those killed in 2009 and 2010 and extracted the PWNs from the pine trees killed in 2010 by the Bearmann funnel method to determine whether those pine trees were killed by PWD or not. In November 2011, we surveyed the pine trees killed in 2011. We examined the emergence holes of the beetles for all pine trees killed in 2010 and feeding wounds for those killed in 2011.

To analyze the spatial distribution patterns of pine trees killed in 2008 (2008KT) and 2009 (2009KT) and those growing at the beginning of each season (2008 and 2009GT), we calculated their mean (m) and mean crowding $\left(\mathrm{m}^{*}\right)$ for 5 quadrat sizes; $1 \times 1 \mathrm{~m}, 2 \times 2 \mathrm{~m}, 4 \times 4 \mathrm{~m}, 5 \times 5 \mathrm{~m}$, and $10 \times 10 \mathrm{~m}$. The mean crowding was calculated by the formula:

$$
\mathrm{m}^{*}=\sum_{\mathrm{j}=1}^{\mathrm{Q}}\left(X_{\mathrm{j}}-1\right) X \mathrm{j} /\left(\sum_{\mathrm{j}=1}^{\mathrm{Q}} X_{\mathrm{j}}\right)
$$

where $X \mathrm{j}$ is the number of pine trees in the $j$-th quadrat and $\mathrm{Q}$ is the number of quadrats on the study plots (Lloyd 1967). If pine trees distributed randomly, $\mathrm{m}^{*}$ is equal to $\mathrm{m}$, and if they distributed aggregately or uniformly, $\mathrm{m}^{*}$ is greater or smaller than $\mathrm{m}$, respectively.

The characteristics of the spatial distribution pattern of the four categories of pine trees (the basic component of distribution and the distribution pattern of the basic component) were analyzed by the unit-size $\mathrm{m}^{*}-\mathrm{m}$ relationship proposed by Iwao (1972). The $\mathrm{m}^{*}$-on-m regression obtained by successive changes in quadrat sizes in a single population shows a characteristic pattern according to the type of distribution and has a turning point around the quadrat size approximately equal to the clump area in colonial distribution.

The relationship of the spatial distribution pattern of 2009KT with that of $2008 \mathrm{KT}$ and pine trees from which JPS adults emerged in 2009 (2009JPST) were examined by the $\kappa$ - index proposed by Iwao (1977). The values of $\kappa$-index were calculated for the five different quadrat sizes by the formula;

$$
k-\operatorname{index}=Q \cdot \sum_{\mathrm{j}=1}^{\mathrm{Q}}\left(X_{\mathrm{Xj}_{\mathrm{j}}} \cdot X_{\mathrm{Yj}_{\mathrm{j}}}\right) /\left(\sum_{\mathrm{j}=1}^{\mathrm{Q}} X_{\mathrm{Xj}} \cdot \sum_{\mathrm{j}=1}^{\mathrm{Q}} X_{\mathrm{Y}_{\mathrm{j}}}\right)
$$

where $\mathrm{Q}$ is the number of quadrats contained on the study plot, $X_{\mathrm{Xj}}$ is the number of $2009 \mathrm{KT}$ in the $j$-th quadrat, and $X_{\mathrm{Yj}}$ is the number of 2009JPST or 2008KT in the $j$-th quadrat. $\kappa$ is equal to unity if both categories of pine trees distributed independently, and greater or smaller than unity if there is a positive or negative association between the spatial distribution patterns of the two categories of pine trees.

\section{Results}

Of the 346 pine trees on the study plot in October 2010, 42, 47, 23, 5 and 1 tree were killed before 2008, in 2008, 2009, 2010, and 2011, respectively (Figure 1). Emergence holes were recorded on 8, 13, and 2 trees killed in 2008, 2009, and 2010, respectively. Feeding wounds were observed on all trees killed in 2009, 2010, and 2011. 
PWNs were extracted from all trees killed in 2010 and 2011.

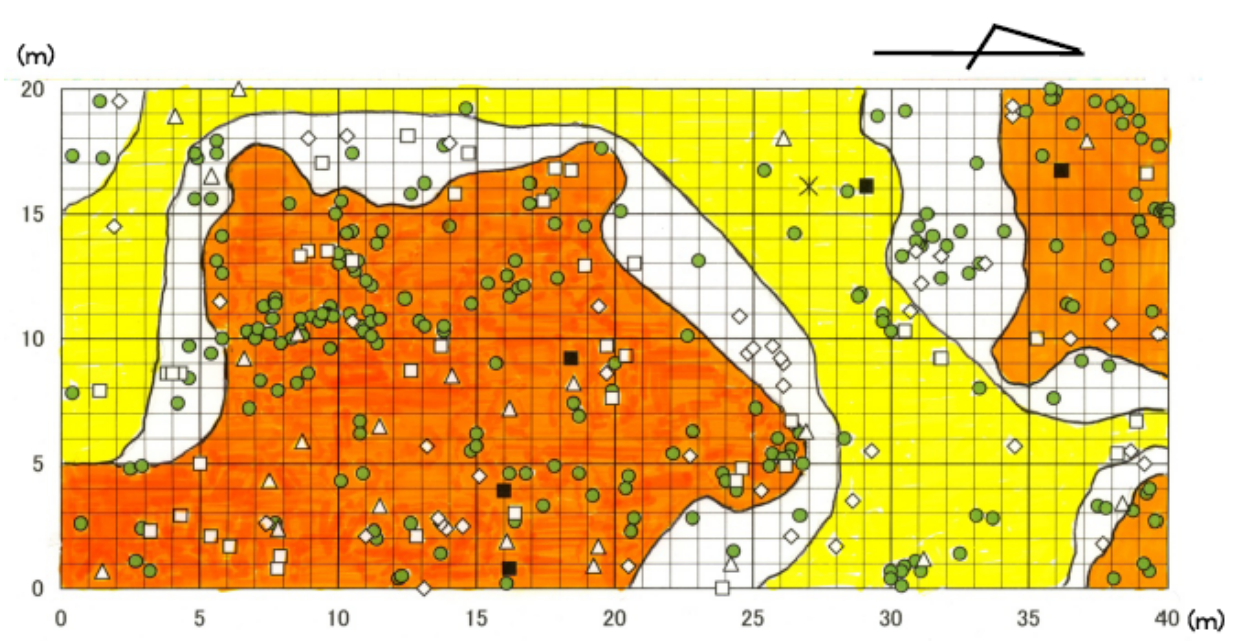

Figure 1. Locations of pine trees alive in November 2011 (green circles), those killed before 2008 (empty squares), and those killed in 2008 (empty rhombs), 2009 (empty triangles), 2010 (solid squares), and 2011 (asterisk) on the study plot

Lava was exposed on the ground surface in patches in the area shown in orange and volcanic ash was accumulated thickly in the area shown in yellow. The area shown in white was the area intermediate between the two, where lava was buried under a thin accumulation of volcanic ash.

The mean tree height and DBH of pine trees growing in October 2010 were $330 \pm 167$ (SD) cm $(119-902 \mathrm{~cm})$ and $3.5 \pm 2.5 \mathrm{~cm}(0.5-14.0 \mathrm{~cm})(\mathrm{n}=229)$, respectively. About $56 \%$ of them were shorter than $3 \mathrm{~m}$, and DBH of about $45 \%$ of the growing pine trees was $1-3 \mathrm{~cm}$ (Figure 2). In 2009 and 2010, pine trees of various sizes were killed (140-659 cm in height, 0.9-11.5 cm in DBH), and the incidence of PWD did not seem to increase with the size of pine trees (Figure 2).
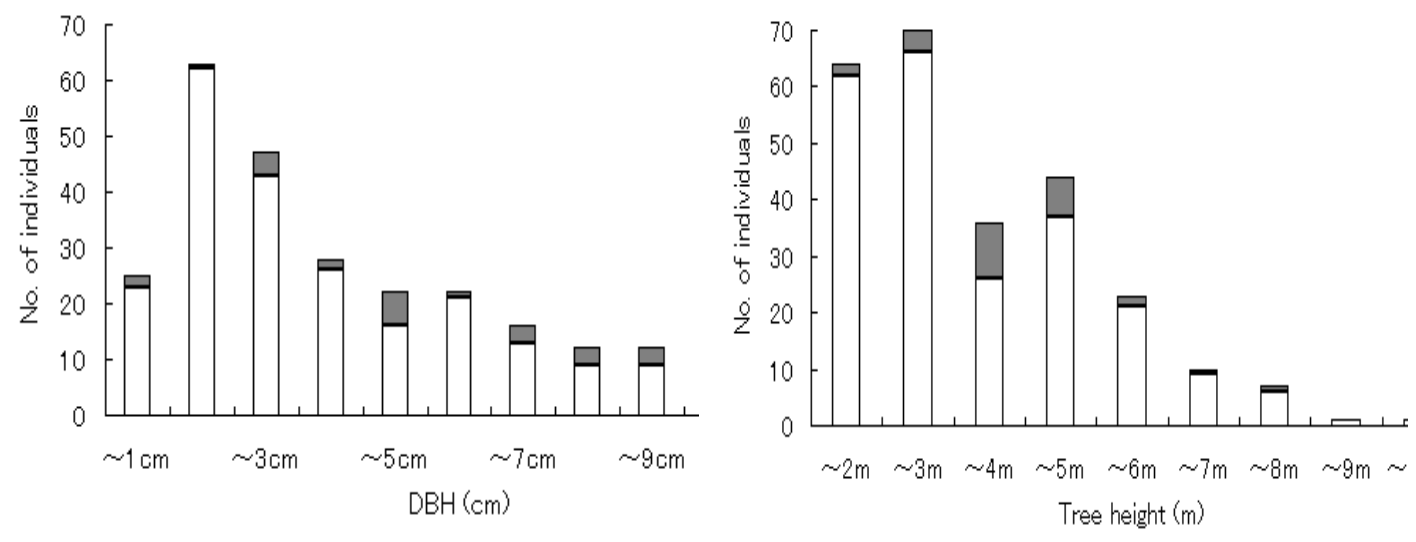

Figure 2. Frequency distributions of tree height (left) and DBH (right) of $P$. thumbergii trees surviving (empty) and those killed by PWD (shaded) in October 2010 on the study plot

More pine trees were growing in the area where lava was exposed on the ground surface in patches, while fewer pine trees were growing in the area where volcanic ash was accumulated thickly (Figure 1). Figures 3 and 4 show that the unit-size $\mathrm{m}^{*}-\mathrm{m}$ relationships for 2008GT and 2009GT and that for 2008KT and 2009KT, respectively. In all four cases, $\mathrm{m}^{*}$ was higher than their corresponding $\mathrm{m}$, showing that these four categories of pine trees distributed aggregately. The regression for 2008 GT and 2009GT showed a turning point at the quadrat 
size of $4 \times 4 \mathrm{~m}$ and the slope became gentler. While, the regression for 2008KT and 2009KT showed two apparent turning points at two quadrat sizes $(4 \times 4 \mathrm{~m}$ and $5 \times 5 \mathrm{~m})$. These results suggest that the basic component of distribution was a loose colony of pine trees occupying an area of $4 \times 4 \mathrm{~m}$ to $5 \times 5 \mathrm{~m}$ for four categories of pine trees and that the colonies of 2008GT and 2009GT distributed randomly and those of 2008KT and 2009KT distributed uniformly.
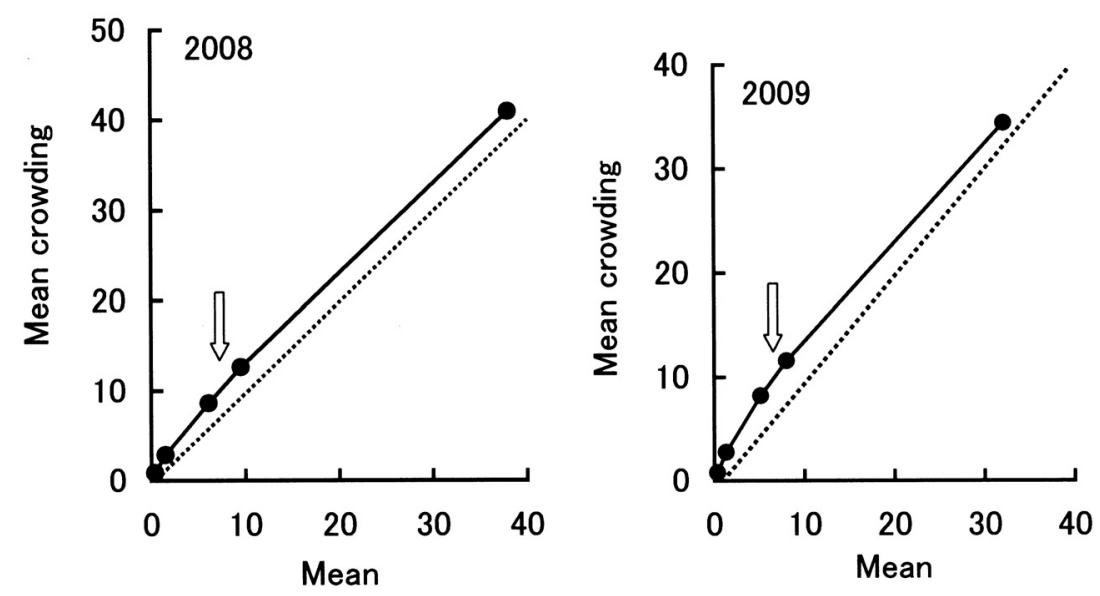

Figure 3. The unit-size $\mathrm{m}^{*}-\mathrm{m}$ relationships for pine trees growing at the beginning of growing season in 2008 and 2009

The dotted lines indicate the Poisson expectations. Arrows show the size of colonies of pine trees.
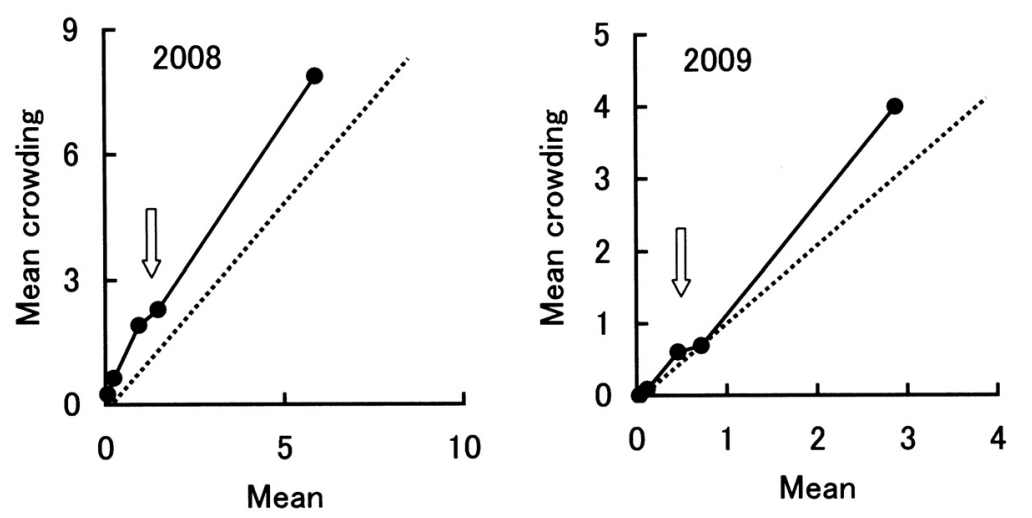

Figure 4. The unit-size $m^{*}-m$ relationship for pine trees killed in 2008 and 2009

The dotted lines indicate the Poisson expectations. Arrows show the size of colonies of pine trees.

The value of $\kappa$ - index calculated for 2009KT and 2008KT was smaller than unity for the sizes of the basic component of the distribution of killed trees, $4 \times 4 \mathrm{~m}$ and $5 \times 5 \mathrm{~m}$ (Table 1). The value of $\kappa$ - index calculated for 2009KT and 2009JPST was smaller than unity for all five quadrat sizes (Table 1). These results suggest that the spatial distribution pattern of 2009KT was exclusive to that of 2008KT and 2009JPST for these quadrat sizes. 
Table 1. $\kappa$ - index calculated for pine trees killed in 2009 (2009KT) and in 2008 (2008KT) and those from which JPS adults emerged in 2009 (2009JPST)

\begin{tabular}{cccccc}
\hline \multirow{2}{*}{ Categories of pine trees } & \multicolumn{5}{c}{ Quadrat sizes $(\mathrm{m} \times \mathrm{m})$} \\
\cline { 2 - 6 } & $1 \times 1$ & $2 \times 2$ & $4 \times 4$ & $5 \times 5$ & $10 \times 10$ \\
\hline $2009 \mathrm{KT}-2008 \mathrm{KT}$ & 1.47 & 0.74 & 0.56 & 0.83 & 1.04 \\
$2009 \mathrm{KT}-2009 \mathrm{JPST}$ & 0.00 & 0.00 & 0.27 & 0.87 & 0.91 \\
\hline
\end{tabular}

\section{Discussion}

In this study, feeding wounds made by the JPS beetles were observed on all pine trees killed in 2009, 2010, and 2011. The PWNs were extracted from all pine trees killed in 2010 and 2011. These results suggest that PWD was probably the only mortality factor of pine trees on the study plot during the study period, 2008-2011. The annual changes in the number of pine trees killed by PWD on the T field (see the text of study site and methods) and the study plot indicate that PWD was decreasing during the study period.

On the study plot, pine trees formed loose colonies of $16-25 \mathrm{~m}^{2}$ in area, and the colonies distributed randomly. Exposed lava and accumulated volcanic ash influenced the number of pine trees growing in these microhabitats (Figure 1). The micro-topographic conditions might be the main factor of the colonial distribution of pine trees growing on the lava field.

PWD killed pine trees of various sizes (Figure 2), and the basic component of the distribution of killed trees was also a loose colony of $16-25 \mathrm{~m}^{2}$ in area as it was for GT (Figures 3 and 4). These results suggest that the spatial distribution pattern of killed trees was not primarily dependent on that of pine trees of a specific size. However, we could not explain why the colonies of killed trees were distributed uniformly, unlike the GT, which were distributed randomly.

The spatial pattern of 2009KT was correlated negatively with those of 2008KT and 2009JPST (Table 1). These results indicate that 2009KT occurred in the colonies of pine trees where no killed trees occurred in 2008. The dispersal pattern of the JPS beetles in the stand should affect the spatial distribution pattern of killed trees in a pine stand. The beetles flew very actively in a sparsely growing stand (Togashi, 1990b). Immature, unmated beetles were more active fliers than mature, mated beetles (Ito, 1982; Togashi, 1990a). Early in the season, the beetles dispersed randomly by flying and distributed independently of trees afflicted with PWD (Togashi, 1989b). All PWNs left from about 30-40 \% of the beetles collected in Sakurajima within 7 days after their emergence under 25 and $30^{\circ} \mathrm{C}$ conditions (Sone et al., 2009). Therefore, on the study plot, the JPS beetles probably flew very actively to sound trees growing in other colonies soon after their emergence. The PWNs might leave the beetles and invade rapidly into sound pine trees when the beetles reached new host pine trees, causing new diseased trees there. As the season progresses, the beetles might be attracted to volatiles emitted from dying or newly killed pine trees (Ikeda \& Oda, 1980; Ikeda et al., 1980b, 1981) and aggregate to the colonies with newly diseased pine trees (Shibata, 1986; Togashi, 1989a). As the results, groups of 2009KT might occur in colonies of pine trees other than those with 2008KT.

The spatial distribution pattern of pine trees killed the previous year should be an important determinant factor of the spatial pattern of PWD in a stand, and Futai (2003) reported that PWD often recurs in the vicinity of the stump of a pine tree killed the previous year in a mature stand of $P$. koraiensis and stressed the importance of asymptomatic carrier trees. However, the negative association of the spatial pattern of 2008KT and 2009KT in this study, namely, 2008KT and 2009KT occurred in different colonies of pine trees, suggests that asymptomatic carrier trees did not influence the spatial pattern of the killed trees. Pine trees growing on the lava field did not have the resistance to PWD inherently, but acquired resistance during the stages from germination to establishment as seedlings through a mutual association with mycorrhizal fungi (Sone et al., 2010). This acquired resistance might conceal the effects of asymptomatic carrier trees on the spreading pattern of PWD in a stand.

The results of this study indicate that the spreading of PWD in a pine stand would differ with the condition of the pine stands, mature or young and dense or sparsely planted, which might affect the flight activity of the JPS beetles and the physiological condition of pine trees. In young, open pine stands, killed trees would not always occur in the vicinity of pine trees killed the previous year probably due to active, random dispersion of the JPS beetles from wilted pine trees where they emerged and rapid invasion of the PWNs into sound pine trees. Therefore, intensive chemical (fumigation with insecticides) and mechanical control practices (cutting and 
chipping of killed trees), which are recommended by the Forest Agency of Japan, should be applied in a wide range around the killed trees to prevent the spreading of PWD.

\section{References}

Futai, K. (2003). Role of asymptomatic carrier trees in epidemic spread of pine wilt disease. Journal of Forest Research, 8, 253-260. http://dx.doi.org/10.1007/s10310-003-0034-2

Ikeda, T., \& Oda, K. (1980). The occurrence of attractiveness for Monochamus alternatus Hope (Coleoptera; Cerambycidae) in nematode-infected pine trees. Journal of Japanese Forestry Society, 62, 432-434.

Ikeda, T., Oda, K., Yamane, A., \& Enda, N. (1980). Volatiles from pine logs as the attractant for the Japanese pine sawyer Monochamus alternatus Hope (Coleoptera; Cerambycidae). Journal of Japanese Forestry Society, 62, 150-152.

Ikeda, T., Yamane, A., Enda, N., Matsuura, K., \& Oda, K. (1981). Attractiveness of chemical treated pine trees for Monochamus alternatus Hope (Coleoptera; Cerambycidae). Journal of Japanese Forestry Society, 63, 201-207.

Ito, K. (1982). The tethered flight of the Japanese pine sawyer, Monochamus alternatus Hope (Coleoptera; Cerambycidae). Journal of Japanese Forestry Society, 64, 395-397.

Iwao, S. (1972). Application of the $\mathrm{m}^{*}-\mathrm{m}$ method to the analysis of spatial patterns by changing the quadrat size. Reseaches on Population Ecology, 14, 97-128. http://dx.doi.org/10.1007/BF02511188

Iwao, S. (1977). Analysis of spatial association between two species based on the interspecies mean crowding. Researches on Population Ecology, 18, 243-260. http://dx.doi.org/10.1007/BF02754097

Lloyd, M. (1967). Mean crowding. Journal of Animal Ecology, 36, 1-30. http://dx.doi.org/10.2307/3012

Mamiya, Y., \& Enda, N. (1972). Transmission of Bursaphelenchus xylophilus (Nematoda: Aphelenchoididae) by Monochamus alternatus (Coleoptera: Cerambycidae). Nematologica, 18, 159-162. http://dx.doi.org/10.1163/187529272X00395

Shibata, E. (1986). Dispersal movement of the adult Japanese pine sawyer, Monochamus alternatus Hope (Coleoptera; Cerambycidae), in a young pine forest. Applied Entomology and Zoology, 21, 184-186.

Sone, K., Iwanaga, Y., \& Hata, K. (2009). Decreased wilting of Japanese black pine saplings by infection of the Japanese pine sawyer adults with entomopathogenic fungus, Beauveria bassiana. Journal of Japanese Forestry Society, 91, 313-317 (in Japanese with English abstract). http://dx.doi.org/10.4005/jjfs.91.313

Sone, K., Hata, K., Sato, Y., \& Nakamura, K. (2002). Invasion and extension of pine wilt disease, and protection practice to pine wilt disease in Sakurajima. Forest Pests, 51, 141-147 (in Japanese).

Sone, K., Yasuda, N., Ookuma, H., Fukuyama, S., \& Nagano, T. (2010). Pine wilt disease-resistance of Pinus thunbergii trees growing on lava terrace in Sakurajima. Research Bulletin of Kagoshima University Forest, 37, 29-36 (in Japanese with English abstract).

Togashi, K. (1980). Preliminary report on the hibernation of the Japanese pine sawyer, Monochamus alternatus Hope, in Ishikawa Prefecture. Bulletin of Ishikawa-ken Forest Experimental Station, 10, $39-50$ (in Japanese with English abstract).

Togashi, K. (1989a). Development of Monochamus alternatus Hope (Coleoptera; Cerambycidae) in Pinus thunbergii trees weakened at different times. Journal of Japanese Forestry Society, 71, 383-386 (in Japanese with English Abstract).

Togashi, K. (1989b). Studies on population dynamics of Monochamus alternatus Hope (Coleoptera; Cerambycidae) and spread of pine wilt disease caused by Bursaphelenchus xylophilus (Nematoda: Aphelenchoididae). Bulletin of Ishikawa-ken Forest Experimental Station, 20, 1-142 (in Japanese with English abstract).

Togashi, K. (1990a). Change in the activity of adult Monochamus alternatus Hope (Coleoptera; Cerambycidae) in relation to age. Applied Entomology and Zoology, 25, 153-159.

Togashi, K. (1990b). A field experiment on dispersal of newly emerged adults of Monochamus alternatus Hope (Coleoptera; Cerambycidae). Researches on Population Ecology, 32, 1-13. http://dx.doi.org/10.1007/BF02512586 